Research Article

\title{
Maritime Pilots' Risky Operational Behavior Analysis Based on Structural Equation Model
}

\author{
Tingliu Xu $\mathbb{D}^{1,2}$ Yingjie Xiao ${ }^{1}{ }^{2}{ }^{2}$ and Zhuohong Jiang ${ }^{3}$ \\ ${ }^{1}$ Faculty of Maritime and Transportation, Ningbo University, Ningbo 315832, China \\ ${ }^{2}$ Merchant Marine College, Shanghai Maritime University, Shanghai 201306, China \\ ${ }^{3}$ Ningbo Pilot Station, Ningbo 315000, China \\ Correspondence should be addressed to Yingjie Xiao; xiaoyj@shmtu.edu.cn
}

Received 4 August 2021; Revised 21 August 2021; Accepted 24 August 2021; Published 27 September 2021

Academic Editor: Daqing Gong

Copyright (C) 2021 Tingliu Xu et al. This is an open access article distributed under the Creative Commons Attribution License, which permits unrestricted use, distribution, and reproduction in any medium, provided the original work is properly cited.

In this paper, a maritime pilots' risky behaviour related factors questionnaire is designed to identify and quantify the factors of maritime pilots' risky operational behaviour. And a questionnaire survey was conducted, which included four scales: risk-taking behavior, risk attitude, operational reliability, and risk perception. On this basis, the Structural Equation Model (SEM) of maritime pilots' risky operational behavior is constructed to explore the internal relationship of the variable factors affecting maritime pilots' operational behavior. The biggest influence on maritime pilots' safety behavior is crowd psychology, which indicates that the maritime pilot's mental health course, the psychological guidance course system, the psychological health consultation management, and safety training should be carried out regularly. Random evaluation and attention are significantly correlated with the risky cognition of maritime pilots. The results also explore that the maritime pilots' risky behavior related factors questionnaire has a good structure, internal consistency, and validity in Chinese maritime pilots, and it is expected to be used for the Chinese maritime pilots' subjective risky behavior self-evaluation. In addition, with empirical evidence for pilotage safety intervention in China, this measurement can also provide scheduling and management decision support for Chinese maritime pilot stations.

\section{Introduction}

The maritime accident at sea is always considerable, and its contributory factor must be assessed [1]. As the greatest risk at sea $[2,3]$, human error is generally considered to be one of the main factors in marine casualties [4], because it is associated with most marine accidents (75\%-96\%) [3]. However, with the vast majority focusing on risky behavior on the road and the air in the literature, there is little literature at the sea, especially among the maritime pilots [5]. The maritime pilots are the operators of the pilotage and the key persons to ensure the safety of the pilotage [6]. Maritime Pilotage is a demanding occupation, where the maritime pilots are always required to meet with irregular working and sleeping time, strong and concentrated extreme temperature changes, bad weather conditions, and frequent exposure to unfamiliarly high-stress working environments, which is always high-risk [7]. Individuals who are always working in high stress and risky environments for a long time may lead to risky behavior performance [8]. Once the maritime pilots' risky operational behaviors appear, it may increase the risk of maritime accidents.

There are a lot of shipwrecks at sea, but once the accidents happen, the consequences will be extremely serious [9]. For example, the 2018 accident of the SANCHI tanker was a typical oil spill resulting from a collision between ships, which caused massive property damage, casualties (only three bodies found and $29 \mathrm{crew}$ members unaccounted for), and a serious impact on the environment [10]. According to China's "Water Traffic Safety Status Report 2018," 237 Chinese vessels were involved in accidents, and 83 sank in 2018, resulting in direct economic losses of US $\$ 290$ million. There have been two serious water traffic accidents, killing more than a dozen people. Therefore, timely 
detection of maritime pilots' risky operational behaviors through effective means will help reduce the occurrence of maritime accidents.

Many studies show that the main reason for many traffic accidents is human risky behavior. The important part of traffic safety management research and practice also includes the dangerous work behavior of marine drivers. Lack of cautious dangerous attitude, blind confidence in work, weak fear of dangerous work behavior, violation of traffic rules, and so on are all manifestations of dangerous work behavior, and these may result in a high rate of ship accidents and casualties. All the illegal activities cause the frequent occurrence of traffic accidents and the severity of accidents. The subjective psychological characteristics of maritime drivers are characterized by dangerous operation behavior. At present, most of the literature mainly studies the relationship between risky behavior and factors such as vision, age, mobility, transcendence, and distraction. However, there is little literature on risk cognition, hazardous attitude, operational confidence, and its exogenous indicators. This paper provides a theoretical basis for the intervention and control of maritime pilots' risky operational behavior.

In this paper, a structural equation model (SEM) of ship Dangerous Operation Behavior is proposed, and the inherent formation mechanism of maritime pilots' risky operational behavior is discussed; the model includes four dimensions: operational confidence, risk cognition, hazardous attitude, and risky operational behaviorr. Risk cognition, operational confidence, and hazardous attitude reflect the mental feelings of maritime pilots and have a direct or indirect influence on dangerous combat behavior. Data were collected by questionnaire survey on maritime pilots' individual Operation Behavior and intention. Based on the theory of structural equation model (SEM), the relationship model between risk management behavior and related intention is established. What is the significant relationship between risk-taking behavior, operational confidence, hazardous attitude, risk cognition, and their secondary exogenous variables? How to implement the strategy of preventing and intervening the dangerous operation behavior and understand the mental mechanism of the maritime pilots according to the results of the structural analysis? These problems are all analyzed by this SEM.

\section{Literature Review}

At present, the domestic and foreign literature on risky behavior mainly focuses on attitude [11, 12], cognition [13], risk perception [14], personality, and risk tolerance [15]. For example, in investigating whether attitudes can predict future traffic risky behavior, Iversen [16] found a high correlation between the dimensions of attitudes and behavior. The attitudes measured in the first survey had a consistent effect on the risky driving behavior measured in the second survey. Ulleberg and Rundmo [17] performed a questionnaire survey of 1932 Norwegian teenagers and found that personality indirectly influenced dangerous driving behavior mainly through attitude determinants. Cyders et al. [18] developed and began to test an indicator of a tendency to act recklessly in response to a positive emotional state, finding that a positive sense of urgency could explain differences in risky behavior, and other measurements of similar impulsive structures cannot explain the difference. Horvath and Zuckerman [19] assessed the relationship between sensation seeking and impulsivity, assessing several aspects of risk, including crime, economic, social aggression, sports, sexual behavior, and risky behavior. Models that identify risk assessment traits as consequences of risk behavior are superior to models that use risk assessment as an intermediary between sensation seeking and risky behavior. Wang and $\mathrm{Xu}$ [20] discovered that young drivers' willingness to engage in continuous lane-changing was influenced by attitude, subjective norms, perceived behavioral control, perceived risk, prototype similarity, and prototype. Al-Wathinani et al. [21] concluded that the behavior among drivers in Saudi Arabia generally matches that in other cultures and countries, with men and young adults taking the most risks while driving. Preventative strategies should be developed and implemented in Saudi Arabia. Mirean and Diaconu-Gherasim [22] found that the participants with higher levels of future time perspective reported higher scores on risk perception. Furthermore, risk perception mediated the relation of past negative and future time perspectives with risky driving behavior.

Much of the research has focused on the external characteristics of risky behavior, including gender [23, 24], age $[25,26]$, intelligence, skills, traffic environment, and intervention policies [27-30], while little attention has been paid to the underlying mechanisms. And most of the literature on maritime pilots focuses on stress, fatigue, and other physical and mental health conditions. Few of the literature deals with the Intrinsic Formation Mechanism of risky operational behavior and related internal influencing factors. Andresen et al. [31] surveyed maritime pilots in seven European countries and found that job satisfaction can be predict how much stress maritime pilots would be able to withstand. Lee et al. [32] found that the increased physical and mental fatigue of maritime pilots will increase the possibility of human error in the course of pilotage and then threaten the safety of pilotage.

\section{Materials and Methods}

\subsection{Methods and Main Content of the Survey}

3.1.1. Operational Confidence. In the beginning, four questions were included in the operational confidence scale. This scale is designed to measure the ability of maritime pilots to assess a variety of circumstances (1) Familiar with the route, everything is under my control, (2) I can often predict whether my maneuvering behavior is dangerous based on experience, (3) I can accurately predict the movements of nearby vessels, (4) I can accurately predict the speed of the ship). However, the definition of self-confidence from a social psychological point of view is that the source of confidence not only includes the affirmation of personal judgment, but also includes the affirmation of manipulation 
technique. In particular, the judgment of ship handling techniques and circumstances is generally based on the maritime pilot's handling experience. Therefore, four questions have been added to the above-mentioned operational confidence scale, which includes ship handling technology credibility, navigational environment judgment ability, and meteorological environment judgment ability credibility (1) I am able to respond to emergencies on the channel, (2) Maneuvering skill can help me out of danger, (3) Start piloting with a few glasses of wine, (4) I am a skilled pilot, so I can exceed the speed limit). Likert scale was used to describe each problem with five points from one to five (Answer category as: 1-Yes, that's true. $5-\mathrm{No}$, that is not true). The higher the score, the less operational confident the participant.

3.1.2. Risk Cognition. The current research shows that risk cognition is an individual's subjective cognition of potential danger, which is generally measured by "emotional attention" and "cognitive evaluation." Therefore, the risk cognition scale mainly includes two dimensions: the degree of attention to the accident and the risk cognition. (1) If the traffic lane is busy, I will sail along the inshore traffic zone; (2) I can sail faster than other vessels around; (3) Views on drunk sailing; (4) Navigate in the opposite traffic lane to overtake other ships; (5) Opinions on navigational violations; (6) I often worry about accidents while piloting; (7) Regarding pilotage, I consider myself a cautious person; (8) The pilotage is unsafe; (9) The possibility of a maritime accident in pilotage; (10) The possibility of a maritime accident in pilotage which causing serious injuries; (11) Traffic accidents happen to us more often than others). Likert scale was used to describe each problem with five points from one to five (Answer category as: 1-Yes, that's true. 5-No, that is not true). The lower the score, the higher the risk of anxiety, and the more serious the consequences of cognitive accidents.

3.1.3. Hazardous Attitude. In the part of hazardous attitude scale, according to the characteristics of maritime pilots, this study is based on two dimensions: "irresponsibility attitude" (1) I am responsible for the safety of others; (2) I try my best to avoid any accidents; (3) If a maritime accident is caused by my mistake, I will feel very guilty; (4) I think every maritime participant should be responsible for himself; (5) The lives of family members are severely affected by maritime accidents) and "violation attitude" (1) When most people do not follow the rules, I will also follow the rules; (2) Obeying the rules of navigation will make me safer; (3) Some navigational violations should be allowed for the safety and emergency reasons; (4) Even for protecting our interests, it is not necessary to violate the rules of navigation; (5) Feeling guilty when violating navigational rules), and four questions from the "following attitude" dimension were added to reflect the maritime pilot's reliance on outside group behavior, (1) I can't violate the rules of navigation by following other ship; (2) If I follow other ship and violate the rules of navigation, I will be charged; (3) I do not think it's safer to sail with others; (4) When I do not know if I can across, it's not accurate to follow other behaviors). Therefore, this paper designs the hazardous attitude scale from three dimensions of maritime pilot's responsibility attitude, rule attitude, and conformity attitude. Likert scale was used to describe each problem with five points from one to five (Answer category as: 1-Yes, that's true. 5-No, that is not true). The higher the score, the higher the hazardous attitude, the lower the sense of responsibility to obey the traffic rules, and the higher the Crowd psychology preference.

3.1.4. Risky Operational Behavior. The maritime pilots' behaviors questionnaire was designed based on the previous risky operational behavior questionnaire of motor vehicles and aircraft and the observation of maritime pilots' dangerous behavior. And it is used to measure negligence (1) Negligence of watching by eye; (2) Use a mobile phone when piloting; (3) Collisions with other ships or facilities due to lack of concentration; (4) Slow down and pass the stern of the other vessel; (5) The other ship suddenly rushed out when leaving the berth; (6) Sailing at night without maintaining night vision.), violation (1) Sailing against regulation; (2) Sailing along the inshore traffic lane all the time which is not allowed or recommended; (3) Berthing without tug assistance when the rule requires; (4) Sailing over the safe speed; (5) Sailing in the wrong direction or traffic lane), aggressive (1) Following extremely close to warning the vessel to give way; (2) Forcing to cut through the lane when the current ship wants to turn without communication; (3) Chase the vessel that provokes you; (4) Try to keep up or overtake faster vessels; (5) Not slow down when approaching the precautionary area), and overtaking behavior. Likert scale was used to describe each problem with five points from one to five (Answer category as: 1-Yes, that's true. 5-No, that is not true). The higher the score, the lower the likelihood of risky operational behavior. The structure of the questionnaire is shown in Table 1.

3.1.5. Other Information. Other information includes basic information (gender, marital status, age, etc.), personal and family income, children, maritime pilots' class, work experience, working hours onboard, working frequency onboard, working distance onboard, and accident experience. Accident experience includes the frequency, severity, and other indicators of accidents that have occurred in the last five years.

3.2. Respondents and Procedure. The presurvey was carried out among maritime pilots at pilot stations all over China through WeChat, telephone, paper, and so on. Through the questionnaire of presurvey, we test the degree of the interviewees' correct understanding of the questionnaire and modify the way of presenting some reserved questions. After items with low reliability (Cronbach's alpha $<0.7$ ) were deleted [27], the formal questionnaire was finally designed.

Formal investigations include random and follow-up investigations. A total of 214 maritime pilots participated anonymously in Ningbo and Shanghai. 5 maritime pilots 
TABLE 1: Structure of the questionnaire.

\begin{tabular}{|c|c|c|}
\hline Dimensions & Sub-scales & Item \\
\hline Operational confidence & $\begin{array}{l}\text { Manipulation } \\
\text { technique }\end{array}$ & $\begin{array}{l}\text { 1. I am able to respond to emergencies on the channel } \\
\text { 2. Maneuvering skill can help me out of danger } \\
\text { 3. start piloting with a few glasses of wine } \\
\text { 4. I am a skilled pilot, so I can exceed the speed limit } \\
\text { 5. Familiar with the route, everything is under my control } \\
\text { 6. I can often predict whether my maneuvering behavior is dangerous based on } \\
\text { experience, } \\
\text { 7. I can accurately predict the movements of nearby vessels } \\
\text { 8. I can accurately predict the speed of the ship }\end{array}$ \\
\hline \multirow{3}{*}{ Risk cognition } & Risk level & $\begin{array}{l}\text { 1. If the traffic lane is busy, I will sail along the inshore traffic zone } \\
\text { 2. I can sail faster than other vessels around } \\
\text { 3. Views on drunk sailing } \\
\text { 4. Navigate in the opposite traffic lane to overtake other ships } \\
\text { 5. Opinions on navigational violations }\end{array}$ \\
\hline & Anxiety level & $\begin{array}{l}\text { 6. I often worry about accidents while piloting } \\
\text { 7. Regarding pilotage, I consider myself a cautious person } \\
\text { 8. The pilotage is unsafe } \\
\text { 9. The possibility of a maritime accident in pilotage }\end{array}$ \\
\hline & Probability of accident & $\begin{array}{l}\text { 10. The possibility of a maritime accident in pilotage which causing serious injuries } \\
\text { 11. Traffic accidents happen to us more often than others }\end{array}$ \\
\hline Hazardous attitude & $\begin{array}{l}\text { Irresponsibility } \\
\text { attitude }\end{array}$ & $\begin{array}{l}\text { 1. I am responsible for the safety of others } \\
\text { 2. I try my best to avoid any accidents } \\
\text { 3. If a maritime accident is caused by my mistake, I will feel very guilty } \\
\text { 4. I think every maritime participant should be responsible for himself } \\
\text { 5. The lives of family members are severely affected by maritime accidents } \\
\text { 6. When most people do not follow the rules, I will also follow the rules; } \\
\text { 7. Obeying the rules of navigation will make me safer } \\
\text { 8. Some navigational violations should be allowed for safety and emergency reasons } \\
\text { 9. Even for protecting our interests, it is not necessary to violate the rules of navigation } \\
\text { 10. Feeling guilty when violating navigational rules } \\
\text { 11. I cannot violate the rules of navigation by following other ship } \\
\text { 12. If I follow other ships and violate the rules of navigation, I will be charged } \\
\text { 13. I do not think it's safer to proceed with others } \\
\text { 14. When I do not know if I can across, it's not accurate to follow other behaviours }\end{array}$ \\
\hline $\begin{array}{l}\text { Risky operational } \\
\text { behavior }\end{array}$ & Negligence & $\begin{array}{l}\text { 1. Negligence of watching by eye } \\
\text { 2. Use a mobile phone when piloting } \\
\text { 3. Collisions with other ships or facilities due to lack of concentration } \\
\text { 4. Slow down and pass the stern of the other vessel } \\
\text { 5. The other ship suddenly rushed out when leaving the berth; } \\
\text { 6. Sailing at night without maintaining night vision } \\
\text { 7. Sailing against regulation } \\
\text { 8. Sailing along the inshore traffic lane all the time which is not allowed or } \\
\text { recommended } \\
\text { 9. Berthing without tug assistance when the rule requires } \\
\text { 10. Sailing over the safe speed; } \\
\text { 11. Sailing in the wrong direction or traffic lane } \\
\text { 12. Following extremely close to warning the vessel ahead to give way } \\
\text { 13. Forcing to cut through the lane when the current ship wants to turn without } \\
\text { communication; } \\
\text { 14. Chase the vessel that provokes you } \\
\text { 15. Try to keep up or overtake faster vessels } \\
\text { 16. Not slow down when approaching the precautionary area } \\
\text { 17. Once I am behind, I want to overtake other vessels } \\
\text { 18. Not give way when other vessel overtaking } \\
\text { 19. Not maintain a safe distance from the vessel in front of you } \\
\text { 20. Much faster than the vessel surrounding you }\end{array}$ \\
\hline
\end{tabular}

gave up the answer sheets for various reasons, and 1 questionnaire was invalid. A total of 208 questionnaires are finally valid.
3.3. Statistical Results. The survey respondents were all with ship experience of the 208 respondents. The average years old of these maritime pilots was 38.184 maritime pilots had 
university degrees or above (88.46\%). 62 maritime pilots were from the only one-child family (29.81\%). 194 maritime pilots' Annual household income was between one and five hundred thousand yuan (93.27\%). However, according to their family life level self-assessment, only 28 maritime pilots thought they are middle-class families $(13.46 \%)$, as 136 were well-off families (65.38\%), and 44 werep families and below (21.15\%).

All maritime pilots have sailing experience. In terms of operational experience, the average operational experience is 8.7 years, ranging from at least 3 years to 35 years. The participants' average daily sailing distance was $40 \mathrm{~nm}$ with a standard deviation of $13.1 \mathrm{~nm}$, and the results showed significant differences in the participants' sailing distance, possibly due to differences in the tasks performed by the maritime pilots. In addition, the average weekly working time of maritime pilots is 4.39 days, and the standard deviation is 2.0 days, which reflects the heavy task of maritime pilots in Shanghai and Ningbo.

In the past five years, 2.9 percent of participants were warned, punished, or even had their licenses revoked for violating the rules. Of the six participants involved in the accident, five involved property damage, and one caused the death of the others and serious injuries requiring medical intervention. Table 2 showed the basic demographic information of the respondents.

\section{Results}

4.1. Internal Consistency and Reliability Analysis. Cronbach's $\alpha$ coefficient is used to verify its internal consistency and reliability. If a scale has $n$ questions, and the Average Correlation Coefficient between questions is $r$, then the normalized coefficient of the scale is as follows:

$$
\alpha=\frac{n r}{(n-1) r+1} .
$$

The value of Cronbach's $\alpha$ coefficient is usually between 0 and 1. If Cronbach's $\alpha$ coefficient does not exceed 0.6, the internal consistency reliability is considered to be insufficient; 0.7-0.8 indicates that the scale has good reliability; 0.8 0.9 indicates that the scale has very good reliability.

Cronbach's $\alpha$ coefficient of the total maritime pilots' risky behavior related factors questionnaire was $0.738,0.909$ for risk level, 0.811 for anxiety level, 0.829 for the probability of an accident, 0.830 for manipulation technique, 0.849 for hazard judgment, 0.929 for irresponsibility attitude, 0.959 for violation attitude, 0.843 for the following attitude, 0.780 for negligence, 0.867 for violation, 0.789 for aggressive, and 0.770 for overtaking. Cronbach's $\alpha$ coefficients of all potential variables were above 0.7 , which had a good internal consistency and reliability.

4.2. Exploratory Factor Analysis (EFA). In order to explore the potential structure of variables, the exploratory factor analysis (EFA) was performed using the principal axis and maximum variance rotation method. The EFA showed that the main factors were of operational confidence, risk cognition, hazardous attitude, and risky operational behaviors. Overall project adjustments were made after some low load items were moved or removed. Among them, the literature of the emotional dimension in this study is not complete overall. According to EFA results, it should be subdivided into two dimensions. Therefore, risk cognition was divided into "risk level," "anxiety level," and "probability of accident" (63.5\% of the total variance). Operational confidence was divided into "manipulation technique" and "hazard judgment" (70.7\% of the total variance). Hazardous attitude was divided into "irresponsibility attitude," "violation attitude," and "following attitude" (68.3\% of the total variance). Risky operational behaviors were divided into "negligence," "violation," "aggressive," and "overtaking" (67.3\% of the total variance).

\subsection{Structural Equation Modeling (SEM)}

4.3.1. SEM Theory. Structural Equation Modeling (SEM) is a statistical method to analyze the relationships between variables based on the covariance matrix of variables. It is an important tool for multivariate data analysis, which generally includes measurement models and structural models, and the measurement equation describes the relationship between the observed dependent variable and the potential independent variable. Based on the measurement model, the structural model is used to represent the relationships between the assumptions that exist $[33,34]$. The measurement model is as follows:

$$
y_{i}=A w_{i}+\varepsilon_{i},
$$

where $Y_{i}$ is the observable variable of $P \times 1, A$ is the factor loading matrix of $p \times q$, and $w_{i}$ is the factor score vector of $q \times 1 ; \varepsilon_{i}$ is the error term of $p \times 1$. And assume that $\varepsilon_{i}$ follows the $N\left[0, \varphi_{\varepsilon}\right]$ distribution; $\varphi_{\varepsilon}$ is a diagonal matrix; $w_{i}$ follows the $N[0, C]$ distribution, and $C$ is a positive covariance matrix.

The structural model is as follows:

$$
g_{i}=B g_{i}+D \xi_{i}+\rho_{i},
$$

where $g_{i}$ and $\xi_{i}$ are the potential variables of $q_{1} \times 1$ and $q_{2} \times 1 ; B$ and $D$ are the unknown parameter matrix; $\rho_{i}$ is the error term. And assume that $\rho_{i}$ follows $N\left[0, \varphi_{\sigma}\right]$ distribution and $\xi_{i}$ follows the $N[0, C]$ distribution, and $\varphi_{\sigma}$ are also diagonal matrices.

Compared with the traditional statistical analysis method, SEM can better explain the measurement error of the potential variable, analyze the relationship between the potential variable and the observed variable, and evaluate the structural relationship between the potential influencing factors. It is one of the best ways to measure potential influences.

4.3.2. Initial Model. Because the initial path relationship is not clear, this paper will first analyze and evaluate the relationship among the factors through correlation analysis and then put forward the hypothesis path relationship according to the relationship among the factors. Finally, the 
TABLE 2: Basic demographic information for the participants $(N=208)$.

\begin{tabular}{|c|c|c|c|}
\hline Category & & Number of persons & Percentage share \\
\hline \multirow{4}{*}{ Age } & $21-30$ & 16 & $7.69 \%$ \\
\hline & $31-40$ & 136 & $65.38 \%$ \\
\hline & $41-50$ & 38 & $18.27 \%$ \\
\hline & $51-60$ & 18 & $8.65 \%$ \\
\hline \multirow{3}{*}{ Education } & Bachelor degree & 170 & $81.73 \%$ \\
\hline & College degree & 24 & $11.54 \%$ \\
\hline & Graduate education & 14 & $6.73 \%$ \\
\hline \multirow{5}{*}{ Maritime pilot level } & Senior pilot & 44 & $21.15 \%$ \\
\hline & Class-one pilot & 66 & $31.73 \%$ \\
\hline & Class-two pilot & 38 & $18.27 \%$ \\
\hline & Class-three pilot & 44 & $21.15 \%$ \\
\hline & Junior pilot & 16 & $7.69 \%$ \\
\hline \multirow{3}{*}{ Child status } & No child & 20 & $9.62 \%$ \\
\hline & One-child & 140 & $67.31 \%$ \\
\hline & Two children & 48 & $23.08 \%$ \\
\hline \multirow{4}{*}{ Marital status } & First marriage & 194 & $93.27 \%$ \\
\hline & Single & 6 & $2.88 \%$ \\
\hline & Separated/divorced & 4 & $1.92 \%$ \\
\hline & Remarriage & 4 & $1.92 \%$ \\
\hline \multirow{4}{*}{ Annual household income (one hundred thousand yuan) } & $<1$ & 10 & $4.81 \%$ \\
\hline & $1 \sim 3$ & 76 & $36.54 \%$ \\
\hline & $3 \sim 5$ & 118 & $56.73 \%$ \\
\hline & $5 \sim 8$ & 4 & $1.92 \%$ \\
\hline
\end{tabular}

path of the internal cause of the variables is adjusted based on the result of parameter estimation. The sample used in all of the above is the complete sample data of the formal questionnaires $(N=208)$.

According to the results of correlation and factor analysis, the initial model was established, including operational confidence, hazardous attitude, risk cognition, and risky operational behavior, which were significantly correlated $(P<0.05)$. Therefore, we proposed six hypothetical paths: (1) from operational confidence to risky operational behavior, (2) from operational confidence to risk cognition, (3) from operational confidence to hazardous attitude, (4) from risk cognition to hazardous attitude, (5) from risk cognition to risky operational behavior, (6) from hazardous attitude to risky operational behavior.

Based on the six route assumptions mentioned above and SEM theory, a maritime pilots' risky operational behavior model, which was shown in Figure 1, is established in this paper. The model includes 12 dimensions of risky rank as the initial factor and 4 dimensions of risk cognition as the higher-order factor. To simplify the model, the factor paths for each high-order potential variable are assumed to be 1 . At the same time, the multiple factors of each initial factor are taken as observable variables and omitted in the simplified model. Finally, in the initial stage, 12 preliminary factors are used as variables for factor analysis to facilitate the verification of the model.

4.3.3. Model Fitting and Revision Process. The Chi-square/ Degree of Freedom (CMIN/DF), Root Mean Square Error Approximation (RMSEA), Comparative Fit Index (CFI), Goodness of Fit Index (GFI), Normed Fit Index (NFI), and
Incremental Fit Index (IFI) were selected as indicators to verify the fit of the model. According to adaptive analysis, the fit index of the structural equation model is as follows: 3.729 was for the ratio of chi-square degrees of freedom (CMIN/DF) (the closer to 1.0, the greater the similarity between the covariance matrix and the estimated covariance matrix, and the better the fit of the model), 0.123 was for RMSEA (0.08 indicates reception fitting, and 0.05 0.08 indicates quite fitting), 0.880 was for CFI $(<0.9), 0.866$ was for GFI $(<0.9)$, 0.854 was for NFI $(<0.9)$, and 0.878 was for IFI $(<0.9)$, but the recommended standard value was higher than 0.9 [35]. Therefore, the theoretical model should be further revised. The theoretical SEM and related parameters were shown in Figure 2. And Table 3 showed the fit index results of the theoretical model.

Based on the analysis of six paths, it is concluded that there are inconspicuous relations in the structural equation model. The revision process was as follows: firstly, the path between "operational confidence" and "risky operational behaviors" was deleted with no significant difference ( $\mathrm{CR}=1.275, P=0.185)$. Secondly, the "risk level" was deleted with 0.315 for the standardized factor load between "risk level" and "risk cognition" (recommended standard value was between 0.4 and 0.96).

The model is modified by establishing the relationship between nonconforming standard terms and modifying a pair of parameters for each release of its independent limiting parameter. The model was then tested for its overall applicability using the maximum likelihood method. The revised data for the final fit are as follows: 2.236 was for the ratio of chi-square degrees of freedom (CMIN/DF) (the closer to 1.0 , the greater the similarity between the 


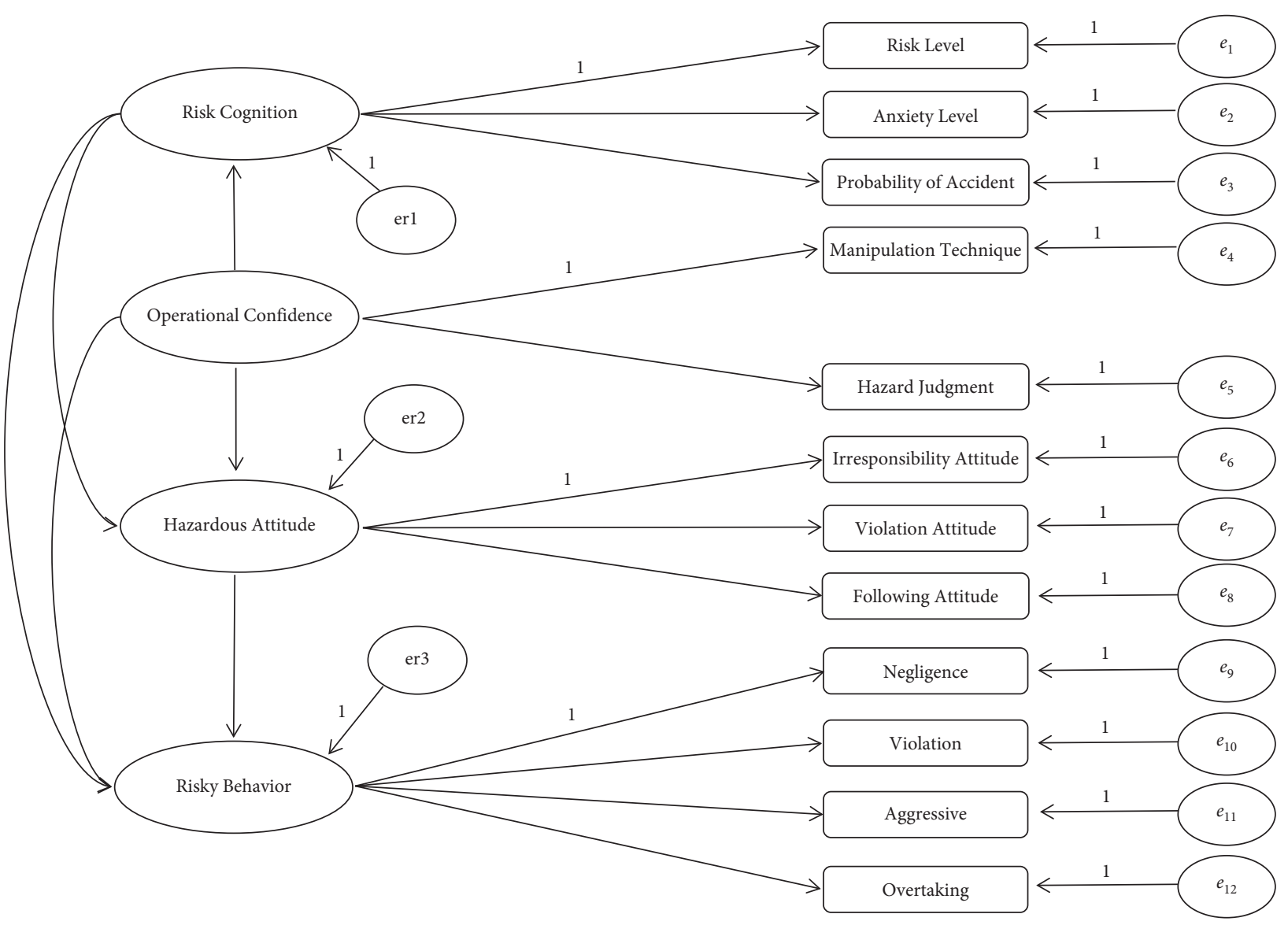

FIGURE 1: The initial model of risky operational behavior.

covariance matrix and the estimated covariance matrix, and the better the fit of the model), 0.029 was for RMSEA $(<0.05$ indicating quite fit), 0.919 was for CFI $(>0.9), 0.950$ was for GFI (>0.9), 0.921 was for NFI (>0.9), and 0.931 was for IFI $(>0.9)$. The structural residual error and the normalized value of the variables are less than 2.58 , which means that the fitting degree of the internal structure of the model is appropriate. These results showed that the modified SEM had a good fit degree. The modified SEM and related parameters were shown in Figure 3. And Table 4 showed the fit index results of the modified model.

\section{Discussion of Results}

5.1. Analyze Each Other's Relationships. According to the structural equation model, the parameters of hazardous attitude and risky operational behavior show that the following attitude of the sea pilot has the most significant effect on the hazardous attitude, and the hazardous attitude is the most important factor. Therefore, more attention should be paid to the psychological management and safety education of maritime pilots. To reduce the hazardous attitude of maritime pilots and to improve their safety behavior, the maritime pilot's mental health course, the psychological guidance course system, and the psychological health consultation management and safety training and education should be carried out regularly.
The average risk level of the questionnaire was 4.40 $(\mathrm{SD}=1.10)$, indicating a higher level of risk cognition. However, when the risk level was raised, the whole risky operational behavior did not change too much, so the risk level was difficult to explain the risk cognition. The relationship between risk cognition including its subvariables "anxiety level," "probability of accident," and dangerous maneuvering behavior shows that the more anxious the maritime pilot is, and the greater the probability of an accident is, the less likely they are to engage in risky operational behavior. This further confirms that maritime pilots with higher safety awareness tend to have higher risk cognition scores and are less likely to engage in risky operational behavior.

Although operational confidence and risky operational behavior have no significant direct influence, they can indirectly influence risky operational behavior through "risk cognition" and "hazardous attitude." According to the "hazard judgment" (0.91) and "manipulation technique" (0.69) in the operational confidence scale, the manipulation technique of the sea pilot has less influence on the operational confidence than the hazard judgment. The definition of "hazard judgment" in the questionnaire mainly refers to the judgment confidence of maritime drivers at work. This kind of judgment confidence is mainly based on their own working experience for navigational behavior and navigational environment. For maritime pilots, in addition to the 


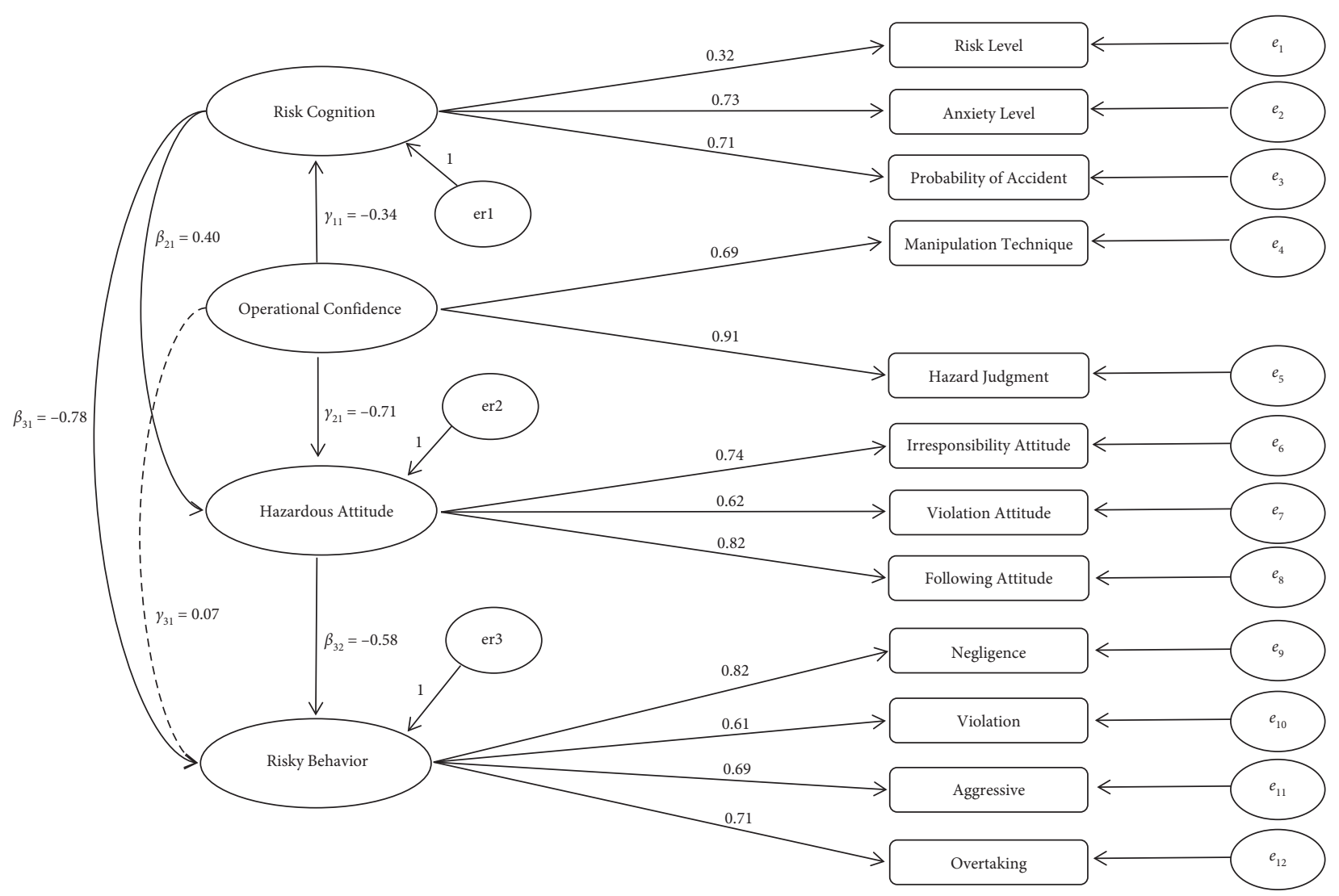

FIGURE 2: Fit results of the initial model.

TABLE 3: Theoretical model fit index results.

\begin{tabular}{lcc}
\hline Model & Standard & Results \\
\hline CMIN/DF & $1-5$ & 3.729 \\
RMSEA & $<0.050$ & 0.123 \\
CFI & $>0.900$ & 0.880 \\
GFI & $>0.900$ & 0.866 \\
NFI & $>0.900$ & 0.854 \\
IFI & $>0.900$ & 0.878 \\
\hline
\end{tabular}

limitations of traffic laws and regulations, confidence in the conduct of navigation and the judgment of the navigational environment is one of the main influencing factors of risky operational behavior. The results show that maritime pilots with high operational confidence take a negative attitude toward risk cognition. And it leads to their risky operational behavior.

5.2. Recommended Management Practices of Avoiding Risky Operational Behaviors. The relationship between risky operational behaviors and hazardous attitudes, which include the irresponsibility attitude, violation attitude, following attitude, and risky operational behaviors, shows that operation safety is necessary to prevent dangerous behavior. Based on the current situation of the port, the competent authorities have effectively formulated the corresponding regulations on the safety supervision and administration of Port pilotage and specified the specific pilotage requirements of maritime pilots at various levels, such as pilotage areas, landing points, and pilotage rules, and through daily supervision to correct and punish pilotage behavior, to standardize pilotage behavior, and strive to avoid and contain dangerous situations and accidents. Therefore, it is suggested that the relevant regulations should be strictly implemented in the port, the VTS function of the port should be given full play, the ship dispatching and pilotage dispatching management should be unified, and the daily supervision of pilotage should be strengthened.

The relationship between risk cognition and risk operational behavior shows that cognition and behavior transform and restrict each other. If the sea pilot has a fluke, where the traffic accident will not occur in their own body, then it is very likely to have the risk of manipulation. Therefore, in order to improve the understanding of dangerous behavior and the severity of traffic accidents, it is suggested that the safety training and emergency preparation of maritime pilots can improve the safety behavior level 


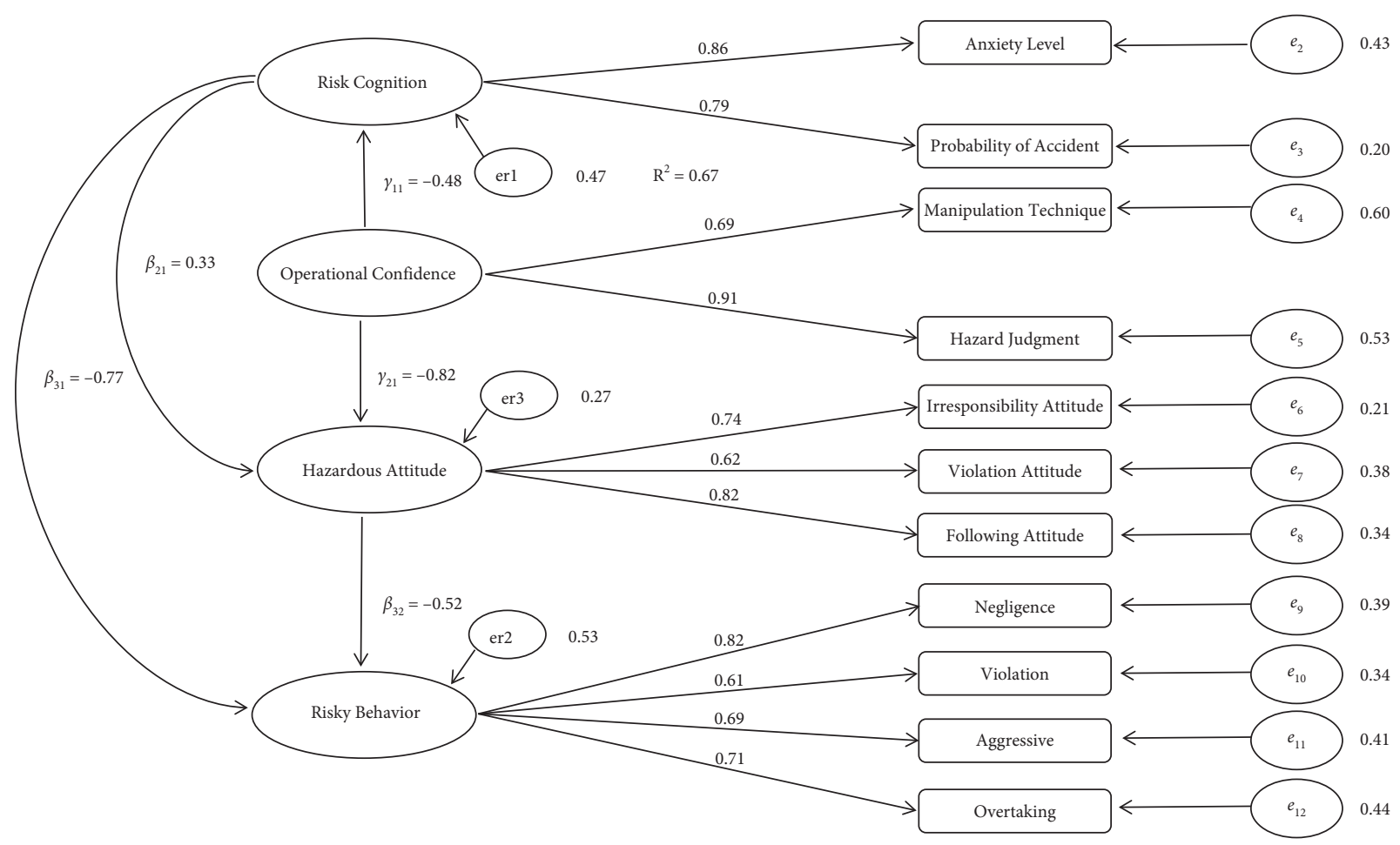

FIGURE 3: Fit results of the revised model.

TABle 4: Modified model fit index results.

\begin{tabular}{lcc}
\hline Model & Standard & Results \\
\hline DF & & 69 \\
CMIN & & 155.295 \\
CMIN/DF & $1-5$ & 2.236 \\
RMSEA & $<0.050$ & 0.029 \\
CFI & $>0.900$ & 0.919 \\
GFI & $>0.900$ & 0.950 \\
NFI & $>0.900$ & 0.921 \\
IFI & $>0.900$ & 0.931 \\
\hline
\end{tabular}

of maritime pilots. This is not a one-off thing, so pilotage safety training needs to maintain a certain frequency, in order to continue to maintain the safety training of maritime pilots to improve safety behavior. The long-term plan of improving the pilot's safety behavior is to change his safety consciousness, so it is necessary to strengthen the safety policy of the pilot organization and enhance the safety attitude and safety communication level of managers, which is the key way to improve the pilot's safety behavior. In addition, the maritime pilots' irregular working time and complex working environment lead to their cognitive and manipulative behavior dullness, which increases the possibility of dangerous cognition and dangerous manipulative behavior. Therefore, the maritime pilot should be guaranteed sufficient rest time during the night shift. It is suggested that the maritime pilot should not exceed 6 hours continuously during the night shift; if more than 6 hours, the maritime pilot should be allowed more than 6 hours rest time to improve the speed of cognition and control behavior.

\section{Conclusions}

This research aims to study the reliability and construct validity of the maritime pilots' risky behavior-related factors questionnaire in maritime pilots. The risky operational behavior scale was designed under Chinese maritime pilots' situation. Furthermore, compared with the traditional statistical methods, the analysis result of SEM is more accurate, using SEM to evaluate the relationships between "risk cognition," "operational confidence," "hazardous attitude," and "risky operational behavior," which quantifies the internal potential causal relationships between influencing factors and risky operational behaviors. In conclusion, the version of maritime pilots' risky behavior related factors questionnaire has good reliability and reasonable validity. Despite this, our survey is a random face-to-face survey, which may lead some shy maritime pilots to deliberately avoid us, making the data not random finally. Furthermore, we estimate that there may be inconsistent consequences 
when using the Chinese version of the maritime pilots' risky behavior related factors questionnaire. However, for some maritime pilots with poor English ability, further use of the Chinese version is still needed to compare the results. So, we suggest that further extensive study is to verify the reliability and validity of the Chinese version in Chinese maritime pilots from the major pilot stations in China to test and compare the changes in their effectiveness and longitudinal time scales. Furthermore, based on our results, we suggest that the original English maritime pilots' risky behavior related factors questionnaire can be applied to the self-assessment of Chinese maritime pilots' risky operational behaviors.

Several limitations should be addressed in this study. Self-reported data may differ somewhat from expectations, because other studies have confirmed that social desirability bias has little effect on participants' responses. Therefore, the existing questionnaire design can be further improved to better capture these potential psychological factors.

This study can provide some useful information for the future development of ship safety interventions. For example, education interventions can be used to improve maritime pilot's attitudes toward traffic safety, and training interventions can be used to improve technical capacity and the ability to risk cognition to reduce the occurrence of risky operational behavior.

\section{Data Availability}

The data used to support the findings of this study are available from the corresponding author upon request.

\section{Conflicts of Interest}

The authors declare that they have no conflicts of interest.

\section{References}

[1] A. Kilic and E. Akdamar, "Investigation of resource distribution based on the relationship between accident regions and accident types," International Journal of Safety and Security Engineering, vol. 10, no. 6, pp. 769-776, 2020.

[2] A. M. Rothblum, "Human error and marine safety," National Safety Council Congress and Expo, vol. 7, 2000.

[3] R. Hanzu-Pazara, E. Barsan, P. Arsenie, L. Chiotoroiu, and G. Raicu, "Reducing of maritime accidents caused by human factors using simulators in training process," Journal of Maritime Research, vol. 5, no. 1, pp. 3-18, 2008.

[4] International Maritime Association, Guidance on Fatigue Mitigation and Management, International Maritime Association, London, UK, 2001.

[5] T. P. Chambers and L. C. Main, "Symptoms of fatigue and coping strategies in maritime pilotage," International Maritime Health, vol. 66, no. 1, pp. 43-48, 2015.

[6] K. Kitamura, K. Murai, Y. Hayashi, T. Fujita, and K. Maenaka, "Measurement and analysis of marine pilot's performance using a large model sensor," in Proceedings of the 2014 IEEE 3rd Global Conference on Consumer Electronics (GCCE), pp. 37-41, Tokyo, Japan, October 2014.

[7] R. M. Darbra, J. F. E. Crawford, C. W. Haley, and R. J. Morrison, "Safety culture and hazard risk perception of
Australian and New Zealand maritime pilots," Marine Policy, vol. 31, no. 6, pp. 736-745, 2007.

[8] C. Hetherington, R. Flin, and K. Mearns, "Safety in shipping: the human element," Journal of Safety Research, vol. 37, no. 4, pp. 401-411, 2006.

[9] Y. Yu, L. Chen, Y. Shu, and W. Zhu, "Evaluation model and management strategy for reducing pollution caused by ship collision in coastal waters," Ocean \& Coastal Management, vol. 203, p. 105446, 2021.

[10] J. Chen, Z. Di, J. Shi et al., "Marine oil spill pollution causes and governance: a case study of Sanchi tanker collision and explosion," Journal of Cleaner Production, vol. 273, p. 122978, 2020.

[11] S. Cox and T. Cox, "The structure of employee attitudes to safety: a European example," Work \& Stress, vol. 5, no. 2, pp. 93-106, 1991.

[12] I. O. Lund and T. Rundmo, "Cross-cultural comparisons of traffic safety, risk perception, attitudes and behaviour," Safety Science, vol. 47, no. 4, pp. 547-553, 2009.

[13] J. F. Yates and E. R. Stone, The Risk Construct, pp. 1-25, John Wiley \& Sons, Chichester, UK, 1992.

[14] X. Chen, E. Xia, and T. He, "Influence of traveller risk perception on the willingness to travel in a major epidemic," International Journal of Sustainable Development and Planning, vol. 15, no. 6, pp. 901-909, 2020.

[15] D. R. Hunter, Risk Perception and Risk Tolerance in Aircraft Pilots, Federal Aviation Administration Office of Aviation Medicine, Washington, DC, USA, 2002.

[16] H. Iversen, "Risk-taking attitudes and risky driving behaviour," Transportation Research Part F: Traffic Psychology and Behaviour, vol. 7, no. 3, pp. 135-150, 2004.

[17] P. Ulleberg and T. Rundmo, "Personality, attitudes and risk perception as predictors of risky driving behaviour among young drivers," Safety Science, vol. 41, no. 5, pp. 427-443, 2003.

[18] M. A. Cyders, G. T. Smith, N. S. Spillane, S. Fischer, A. M. Annus, and C. Peterson, "Integration of impulsivity and positive mood to predict risky behavior: development and validation of a measure of positive urgency," Psychological Assessment, vol. 19, no. 1, pp. 107-118, 2007.

[19] P. Horvath and M. Zuckerman, "Sensation seeking, risk appraisal, and risky behavior," Personality and Individual Differences, vol. 14, no. 1, pp. 41-52, 1993.

[20] X. Wang and L. Xu, "Factors influencing young drivers' willingness to engage in risky driving behavior: continuous lane-changing," Sustainability, vol. 13, no. 11, pp. 1-18, 2021.

[21] A. M. Al-Wathinani, D. C. Schwebel, A. H. Al-Nasser et al., "The prevalence of risky driving habits in Riyadh, Saudi Arabia," Sustainability, vol. 13, no. 13, p. 7338, 2021.

[22] C. Mirean and L. R. Diaconu-Gherasim, "Time perspective, risk perception on the road, and risky driving behavior," Current Psychology, vol. 2021, no. 12, 10 pages, 2021.

[23] J. P. Byrnes, D. C. Miller, and W. D. Schafer, "Gender differences in risk taking: a meta-analysis," Psychological Bulletin, vol. 125, no. 3, pp. 367-383, 1999.

[24] M.-A. Granié, "Effects of gender, sex-stereotype conformity, age and internalization on risk-taking among adolescent pedestrians," Safety Science, vol. 47, no. 9, pp. 1277-1283, 2009.

[25] V. H. Vroom and B. Pahl, "Relationship between age and risk taking among managers," Journal of Applied Psychology, vol. 55, no. 5, pp. 399-405, 1971.

[26] R. A. Retting, R. G. Ulmer, and A. F. Williams, "Prevalence and characteristics of red light running crashes in the United 
States," Accident Analysis \& Prevention, vol. 31, no. 6, pp. 687-694, 1999.

[27] G. Cocolas and B. Sleath, "Relationship between selected personality traits and citation for violating pharmacy board regulations," American Journal of Health-System Pharmacy, vol. 57, no. 5, pp. 456-460, 2000.

[28] B. Scott-Parker, B. Watson, and M. J. King, "Understanding the psychosocial factors influencing the risky behaviour of young drivers," Transportation Research Part F: Traffic Psychology and Behaviour, vol. 12, no. 6, pp. 470-482, 2009.

[29] B. Molesworth, M. W. Wiggins, and D. O’Hare, "Improving pilots' risk assessment skills in low-flying operations: the role of feedback and experience," Accident Analysis \& Prevention, vol. 38, no. 5, pp. 954-960, 2006.

[30] M. Hontvedt, "Professional vision in simulated environments - examining professional maritime pilots' performance of work tasks in a full-mission ship simulator," Learning, Culture and Social Interaction, vol. 7, pp. 71-84, 2015.

[31] M. Andresen, M. E. Domsch, and A. H. Cascorbi, "Working unusual hours and its relationship to job satisfaction: a study of European maritime pilots," Journal of Labor Research, vol. 28, no. 4, pp. 714-734, 2007.

[32] J.-W. Lee, E.-W. Kim, and C.-H. Lee, "A basic study on the accident prevention measures of maritime pilots during embarkation and disembarkation," Journal of Fishries and Marine Sciences Education, vol. 29, no. 1, pp. 137-147, 2017.

[33] Y. Zhang, W. Shao, M. Zhang, H. Li, S. Yin, and Y. Xu, "Analysis 320 coal mine accidents using structural equation modeling with unsafe conditions of the rules and regulations as exogenous variables," Accident Analysis \& Prevention, vol. 92, pp. 189-201, 2016.

[34] J. Zhang, F. Wang, C. Shao, and X. Mi, "Structural equation modelling of household long-distance flexible travel behavior," International Journal of Sustainable Development and Planning, vol. 15, no. 4, pp. 461-467, 2020.

[35] L. T. Hu and P. M. Bentler, "Cutoff criteria for fit indexes in covariance structure analysis: conventional criteria versus new alternatives," Structural Equation Modeling: A Multidisciplinary Journal, vol. 6, no. 1, pp. 1-55, 1999. 